\title{
Variations in the Shape and Dimension of the Suprascapular Notch in Dried Human Scapula-An Osteological Study with its Clinical Implications
}

\author{
APURBA PATRA, MANJEET SINGH, HARSIMARJIT KAUR
}

\section{ABSTRACT}

Introduction: The suprascapular notch is a depression on the superior border of scapula which gives passage to the suprascapular nerve to enter the supraspinatus fossa. During its course there is a chance of entrapment of the nerve while in the notch due to its variant shapes and dimensions which leads to suprascapular nerve entrapment syndrome

Aim: The purpose of the study was to determine the variations of the shape and dimensions of suprascapular notch of scapula because these parameters may be the causative factors in nerve compression.

Materials and Methods: A total 110 dried human scapula of both sides were included in the study. First they were grossly examined for variations in shape of the notches. Then vertical and transverse dimensions of the notches were measured with the help of digital vernier calliper.

Results: As per classification by shape we found 43 ' $J$ ' shaped (39.09\%), 35 'U' shaped (31.81\%), 10 'V' shaped $(9.09 \%)$, indentation in eight cases $(7.27 \%)$, absent in five (4.54\%), partial ossification of STSL in four (3.63\%) and complete ossification in five $(4.54 \%)$ scapulae. The results were also analysed according to Natsis classification after excluding the Scapulae with indentation and partial ossification of ligament. Five (5.1\%) scapulae Type I, sixty six scapulae (67.34\%) had Type II, 14 scapulae (14.28\%) had Type III, five (5.1\%) had Type IV and none (0\%) had Type V. We also found eight scapulae (8.16\%) with transverse diameter equal to the vertical diameter $(\mathrm{Td}=\mathrm{VI})$.

Conclusion: The present study showed various types of suprascapular notches. Out of these lqbal type ' $U$ ' and Natsis type II were most predominant. In both the cases chance of suprascapular nerve compression is less as more space is available to the nerve. The present study also showed five cases of completely ossified STSL where chances of impingement are higher. Since, these anatomical variations are not uncommon in population so there is a need for clinicians to have precise anatomical knowledge of SSN before making proper diagnosis and planning for surgical interventions of suprascapular nerve entrapment syndrome. We hope our study will be helpful in providing anatomical knowledge to the clinicians.

\section{INTRODUCTION}

The suprascapular notch (SSN) is a depression present on the lateral aspect of superior border scapula just medial to the coracoid process. In few cases this notch is transformed into a foramen due to ossification of superior transverse scapular ligament (STSL) and serves as a bony tunnel for suprascapular nerve. The SSN is the main site of suprascapular nerve compression, which may result in significant dysfunction of rotator cuff. This pathology was first described as suprascapular nerve entrapment syndrome by Kopell and Thompson [1]. This disease is characterized by dull aching pain over the posterolateral region of the shoulder, atrophy of the supraspinatus and infraspinatus muscles and weakness during external rotation and initiation of shoulder abduction [2,3]. The shape and size of the SSN is the most important causal factor in the etiopathogenesis of suprascapular nerve entrapment syndrome [4,5]. A narrow SSN may predispose an individual to this entrapment neuropathy [6]. According to previous literatures a $\mathrm{V}$-shaped notch is more likely to be associated with nerve entrapment [7]. Therefore, sound knowledge of the anatomy and morphology of the suprascapular region, especially variations in shape and size of SSN and ossification 
of STSL, are particularly important in various surgical techniques associated with arthroscopic suprascapular nerve decompression [8-10]. A precise anatomical knowledge of the shoulder-girdle region is of great importance in order to avoid iatrogenic neurological complications while performing open, arthroscopic or arthroscopically assisted surgical procedures. In our opinion this osteological study provides a comprehensive anatomical and morphological description of SSN based on its specific geometrical parameters and describes almost all its variations.

\section{MATERIALS AND METHODS}

It was an observational study, total 110 dried human scapulae were collected from bone room of Anatomy Department of Government Medical College, Patiala and grossly examined over a period of six months in the year of 2014, irrespective of age, sex, gender, race and left or right sidedness. Defective and broken scapulae were excluded from the study. The following observations were made -

1. Various shapes of SSN

2. Absence of SSN and

3. Presence of suprascapular foramina instead of SSN (Ossification of superior transverse scapular ligament).

4. Vertical and transverse dimensions of suprascapular notch.

On gross examination, the SSN was classified into three distinct types as proposed by lqbal et al., [11] namely the V-shaped SSN, defined as having medial and lateral sidewalls converged into a narrow base; a U-shaped SSN, defined as having approximately parallel sides with a rounded base; a V-shaped SSN and J shaped SSN. To classify the notch as proposed by Natsis et al., [5] the vertical and transverse dimensions of SSN were also measured using digital vernier calliper. The Scapulae with indentation and partial ossification of ligament were excluded from the measurement. Transverse diameter is the distance between the two edges of the notch and vertical diameter is the distance between the deepest point of the base of the notch to the midpoint of the line joining the two edges.

\section{RESULTS}

In this study three different types of notches were observed along with partial or complete ossification of STSL. Depending on the shape of the notch, scapulae were grouped [Table/ Fig-1] following the lqbal classification [11]. Of these scapulae, 43(39.09\%) showed 'J' shaped [Table/Fig-2], 35(31.81\%) 'U' shaped [Table/Fig-3], and 10(9.09\%) 'V' shaped [Table/ Fig-4] suprascapular notches. In eight (7.27\%) cases an Indentation [Table/Fig-5] was seen instead of notch and five (4.54\%) scapulae were without discrete notch [Table/Fig-6], four (3.63\%) bones with ' $U$ ' shaped notches showed partial ossification [Table/Fig-7] and five (4.54\%) bones showed complete ossification [Table/Fig-8].

\begin{tabular}{|l|c|}
\hline Shape & No. of scapulae \\
\hline J shape & $43(39.09 \%)$ \\
\hline U shape & $35(31.81 \%)$ \\
\hline V shape & $10(9.09 \%)$ \\
\hline Indentation & $8(7.27 \%)$ \\
\hline Absent & $5(4.54 \%)$ \\
\hline Partial Ossification & $4(3.63 \%)$ \\
\hline Complete Ossification & $5(4.54 \%)$ \\
\hline Total & $110(100 \%)$ \\
\hline
\end{tabular}

[Table/Fig-1]: Showing classification of SSN according to shape.
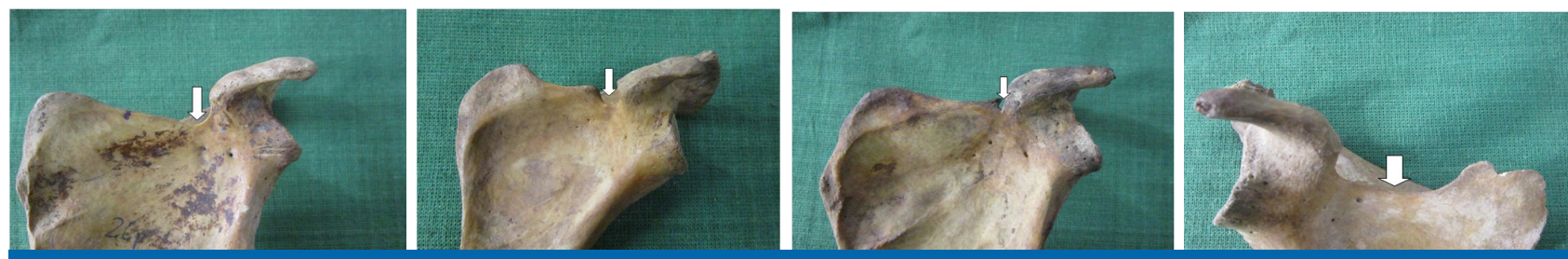

[Table/Fig-2]: Scapula with 'J' shaped notch. [Table/Fig-3]: Scapula with 'U' shaped notch.[Table/Fig-4]: Scapula with 'V' shaped notch. [Table/Fig-5]: Scapula with Indentation.
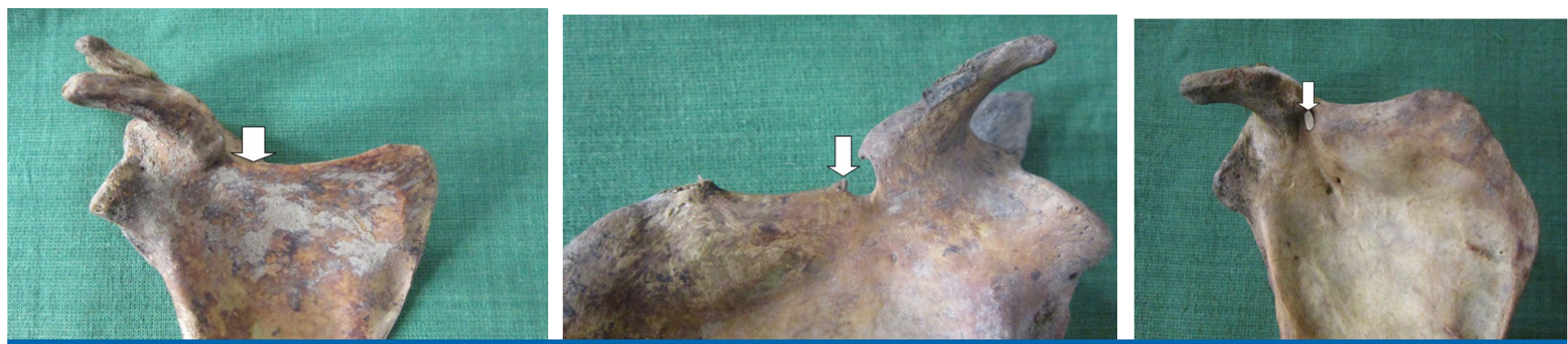

[Table/Fig-6]: Scapula without discrete notch. [Table/Fig-7]: Scapula with partial ossification of STSL. [Table/Fig-8]: Scapula with complete ossification of STSL converting notch into foramen. 


\begin{tabular}{l|c|}
\hline Type & No. of Scapulae \\
\hline I (Absence) & $5(5.1 \%)$ \\
\hline II (Td>VI) & $66(67.34 \%)$ \\
\hline III (Vl>Td) & $14(14.28 \%)$ \\
\hline IV (Bony Foramen) & $5(5.1 \%)$ \\
\hline V (Notch and Foramen) & $0(0 \%)$ \\
\hline Total & $98(100 \%)$ \\
\hline $\begin{array}{l}\text { [Table/Fig-9]: Showing distribution of SSN according to Natsis } \\
\text { classification. }\end{array}$ \\
* Remaining 12 scapulae were not included in the Natsis classification as 8 \\
showed Td = V1 and 4 showed partial ossification.
\end{tabular}

Depending on the dimensions of SSN, scapulae were grouped as proposed by Natsis et al. This study observed five scapulae (5.1\%) without a discrete notch (Type I), 66 scapulae (67.34\%) showed notches where transverse diameter was more than vertical diameter (Type II), in 14 scapulae (14.28\%) vertical diameter was more than transverse diameter (Type III) and five scapulae (5.1\%) had ossification of the transverse scapular ligament (Type IV) [Table/Fig-9].

Apart from those classified in the Natsis classification, our study also found one more type in eight scapulae (8.16\%) where transverse diameter was equal to the vertical diameter. al., [12], Bayramoglu et al., [13], Sinkeet et al., [14] have classified SSN on the basis of morphological appearance into two types - ' $U$ ' and ' $V$ ' and found ' $U$ ' shaped notch to be the most common variety. labal et al., [11] classified SSN into three types - 'U', 'V', J' based on their shapes on gross examination. Soni et al., [15] reported five types of SSN as 'U', 'V', 'J', indentation and absence of notch. The present study predominantly showed labal type ' $U$ ' shaped notches. The results of the present study compared with those of previous studies based on shape are tabulated in [Table/Fig-10].

Nastis et al., [5] classified SSN based on vertical and transverse diameter measurements and Polguj et al.,[20] assessed SSN using three geometrical parameters such as maximal depth, superior and middle transverse diameter and included one more type of SSN in his classification where $\mathrm{Td}=\mathrm{VI}$ as found in our study also. The present study predominantly showed Natsis type II suprascapular notches where the transverse diameter is more than the vertical diameter. In both the predominantly found ' $U$ ' shaped and Natsis type II SSNs in our study, there are less chances of suprascapular nerve entrapment syndrome as more space is available for the suprascapular nerve [Table/Fig-11].

In our study, the frequency of scapulae with a bony foramen was $4.54 \%$ of all cases, which was higher than that seen by

\begin{tabular}{|c|c|c|c|c|c|c|c|c|}
\hline \multirow[t]{2}{*}{ Shape } & \multicolumn{7}{|c|}{ Previous Studies } & \multirow{2}{*}{$\begin{array}{l}\text { Present } \\
\text { Study (\%) }\end{array}$} \\
\hline & $\begin{array}{c}\text { lqbal } \\
\text { et al., [11] }\end{array}$ & $\begin{array}{l}\text { Sinkeet } \\
\text { et al., [14] }\end{array}$ & $\begin{array}{l}\text { Duparc } \\
\text { et al., [16] }\end{array}$ & $\begin{array}{l}\text { Soni } \\
\text { et al., [15] }\end{array}$ & $\begin{array}{l}\text { Vasudha } \\
\text { et al., [17] }\end{array}$ & $\begin{array}{l}\text { Patel } \\
\text { et al., [18] }\end{array}$ & $\begin{array}{l}\text { Nagraj } \\
\text { et al., [19] }\end{array}$ & \\
\hline J Shape & 22 & - & - & 27 & 19.13 & 35 & 43.26 & 39.09 \\
\hline U Shape & 13.2 & 21 & 63.3 & 58 & 12.16 & 47.5 & 26.92 & 31.81 \\
\hline V Shape & 20 & 5.18 & 36.7 & 7 & - & 7.5 & 1.92 & 9.09 \\
\hline Indentation & 33.5 & - & - & 3 & 7.82 & - & 2.88 & 7.27 \\
\hline Absent & 22.5 & 2.12 & - & 2 & 6.08 & 6.25 & 23 & 4.54 \\
\hline
\end{tabular}

[Table/Fig-10]: Showing comparison of percentage of distribution of suprascapular notch according to shape of present study to that of previous studies.

\begin{tabular}{|l|c|c|c|c|c|c|c|}
\hline Type & $\begin{array}{c}\text { Natsis } \\
\text { et al., [5] }\end{array}$ & $\begin{array}{c}\text { Wang } \\
\text { et al., [21] }\end{array}$ & $\begin{array}{c}\text { Mehdy } \\
\text { et al., [22] }\end{array}$ & $\begin{array}{c}\text { Vandana } \\
\text { et al., [23] }\end{array}$ & $\begin{array}{c}\text { Shivaleela } \\
\text { et al., [24] }\end{array}$ & $\begin{array}{c}\text { Sharma } \\
\text { et al., [25] }\end{array}$ & $\begin{array}{c}\text { Present } \\
\text { Study (\%) }\end{array}$ \\
\hline I (Absence) & 8.3 & 28 & 6.06 & 4.8 & 14.70 & 20 & 5.1 \\
\hline II (Td>Vl) & 41.85 & 58.16 & 45.45 & 70.1 & 70.58 & 39 & 67.34 \\
\hline III (Vl>Td) & 41.85 & 28.23 & 43.93 & 8 & 12.78 & 34 & 14.28 \\
\hline IV (Bony Foramen) & 7.3 & 3 & 3.03 & 13.7 & 1.96 & 5 & 5.1 \\
\hline V (Notch and Foramen) & 0.7 & 0 & 1.5 & 0 & 0 & 2 & 0 \\
\hline
\end{tabular}

[Table/Fig-11]: Showing comparison of percentage of distribution of suprascapular notch according to Natsis classification of present study to that of previous studies.

\section{DISCUSSION}

Knowledge of detail anatomy of SSN is necessary for proper diagnosis and treatment of shoulder girdle disorder. Though there are various literatures describing SSN, very few of them highlight on both of its qualitative and quantitative anatomy. In the present study an effort has been made to classify SSN based on its shape and dimensions.

Various authors have classified SSN based on certain parameters and gross examination of its shape. Ticker et
Sinkeet et al., [14] (3\%), Tubbs et al., [26] (3.7\%), Rengachary et al., [6] (4\%) and Sangam et al., [27] (1.93\%). However it was lower than that described by Natsis et al., [5] (7.3\%), Bayramoglu et al., [13] (12.5\%), Mistry et al., [28] (19.44\%), Vasudha et al., [17] (6\%) and Kannan et al., [29] (10\%). Ossification of superior transverse scapular ligament narrows the space for the suprascapular nerve which irritates it during different shoulder movements thereby increasing the likelihood of suprascapular nerve entrapment. [Table/Fig-12]. 


\begin{tabular}{|l|c|c|c|}
\hline Authors & No. of scapulae studied & No. of scapulae with suprascapular foramen & Percentage (\%) \\
\hline Soni et al., [15] & 100 & 3 & 3 \\
\hline Reddy sangam et al., [27] & 104 & 2 & 1.93 \\
\hline Vyas et al., [30] & 300 & 11 & 3.67 \\
\hline Kalpana et al., [31] & 100 & 2 & 2 \\
\hline Patel et al., [18] & 80 & 3 & 3.75 \\
\hline Vandana et al., [23] & 134 & 17 & 12.6 \\
\hline Jadhav et al., [32] & 350 & 37 & 10.57 \\
\hline Present study & 110 & 5 & 4.54 \\
\hline
\end{tabular}

\section{CONCLUSION}

The suprascapular nerve is very intimately related to the SSN while passing through it. Variations in shape and size can be considered as a possible aetiological factor in nerve impingement. Moreover, ossification of STSL converts the notch into foramen and reduces the space available to the nerve leading to suprascapular nerve entrapment syndrome characterized by pain during initiation of shoulder abduction. The present study showed various types of suprascapular notches. Out of these lqbal type ' $U$ ' and Natsis type II were most predominant. In both these cases chance of nerve compression is less as more space is available to the nerve. The present study also showed five cases of completely ossified STSL where chances of impingement is higher. Since these anatomical variations are not uncommon in population so there is a need for clinicians to have precise anatomical knowledge of SSN before making proper diagnosis and planning of surgical interventions. We hope our study will be helpful in providing anatomical knowledge to the clinicians.

\section{REFERENCES}

[1] Kopell HP, Thompson WA. Pain and the frozen shoulder. Surg Gynecol Obstet. 1959;109:92-96.

[2] Antoniou J, Tae SK, Williams GR, Bird S, Ramsey ML, lanotti JP. Suprascapular neuropathy: Variability in the diagnosis, treatment and outcome. Clin Orthop Relat Res. 2001;386:131-38.

[3] Cummins CA, Messer TM, Nuber GW. Suprascapular nerve entrapment. J Bone joint surg Am. 2000;82:415-24.

[4] Dunkelgrun M, lesaka K, Park SS, Kummer FJ, Zuckerman JD. Inter observer reliability and intra observer reproducibility in suprascapular notch typing. Bull Hosp Joint Dis. 2003;61:118-22.

[5] Natsis K, Totlis T, Tsikaras P, Appell HJ, Skandalakis P, Koebke J. Proposal for classification of the suprascapular notch: a study on 423 dried scapulas. Clin Anat. 2007;20:135-39.

[6] Rengachary SS, Burr D, Lucas S, Hassanein KM, Mohn MP, Matzke H. Suprascapular entrapment neuropathy: a clinical, anatomical, and comparative study. Part 2: anatomical study. Neurosurg.1979;5:447-51.

[7] Antoniadis G, Richter HP, Rath S, Braun V, Moese G. Suprascapular nerve entrapment: experience with 28 cases. J Neurosurg. 1996;85:1020-25.
[8] Barwood SA, Burkhart SS, Lo IK. Arthroscopic suprascapular nerve release at the suprascapular notch in a cadaveric model: an anatomic approach. Arthroscopy. 2007;23:221-25.

[9] Bhatia DN, de Beer JF, van Rooyen KS, du Toit DF. Arthroscopic suprascapular nerve decompression at the suprascapular notch. Arthroscopy. 2006;22:1009-13.

[10] Lafosse L, Tomasi A, Corbett S, Baier G, Willems K, Gobezie R. Arthroscopic release of suprascapular nerve entrapment at the suprascapular notch: technique and preliminary results. Arthroscopy. 2007;23:34-42.

[11] lqbal K, lqbal R, Khan SG. Anatomical variations in shape of suprascapular notch of scapula. J Morphol Sci. 2010;27:1-2.

[12] Ticker JB, Djurasovic M, Strauch RJ, April EW, Pollock RG, Flatow EL et al. The incidence of ganglion cysts and other variations in anatomy along the course of the suprascapular nerve. J Shoulder Elbow Surg. 1998;7:472-78.

[13] Bayramoglu A, Demiryürek D, Tüccar E, Erbil M, Aldur MM, Tetik O et al. Variations in anatomy at the suprascapular notch possibly causing suprascapular nerve entrapment: An anatomical study. Knee Surg Sports Traumatol Arthrosc. 2003;11:393-98.

[14] Sinkeet SR. The suprascapular notch: its morphology and distance from the glenoid cavity in a Kenyan population; Folia Morphol. 2010;69:241-45.

[15] Soni G, Malik VS, Shukla L, Chabbra S, Gaur N. Morphometric Analysis of the Suprascapular Notch. The Internet $\mathrm{J}$ Biol Anthropol. 2012;5(1):DOI:10.5580/2B19.

[16] Duparc F, Coquerel D, Ozeel J, Noyon M, Gerometta A, Michot C. Anatomical basis of the suprascapular nerve entrapment and clinical relevance of the supraspinatus fascia. Surg Radiol Anat. 2010;32:277-84.

[17] VasudhaTK, Shetty A, GowdS, Rajasekhar SSSN. Morphological study on suprascapular notch and superior transverse scapular ligaments in human scapulae. Int $\mathrm{J}$ Med Res Health Sci. 2013;2(4):793-98.

[18] Patel P, Patel SV, Patel SM, Jotania B, Chavda S, Patel D. Study of variations in the shape of the suprascapular notch in dried human scapula. Int J Biol Med Res. 2013;4(2):3162-64.

[19] Nagaraj S, Krishnaiah M, Kumar P, Sherke AR. Study of morphological variations of suprascapular notch. IOSR-JDMS. 2014;13(6):121-23.

[20] Polguj M, Jedrzejewski K, Podgorski M, Topo M. Correlation between morphometry of the suprascapular notch and anthropometric measurements of the scapula. Folia Morphol. 2011;70:109-15. 
[21] Wang HJ, Chen C, Wu LP, Pan CQ, Zhang WJ, Li YK. Variable morphology of the suprascapular notch: an investigation and quantitative measurements in Chinese population. Clin Anat. 2011;24(1):47-55.

[22] Mahdy AA, Shehab AA. Morphometric variations of the suprascapular notch as a potential cause of neuropathy: anatomical study. J Am Sci. 2013;9(3):189-97.

[23] Vandana R, Patil S. Morphometric study of suprascapular notch. NJCA. 2013;2(3):140-44.

[24] Shivaleela C, Archana BJ, Kumar GV, Swetha R, Lakshmiprabha $\mathrm{S}$. Morphometric analysis of suprascapular notch in human adult scapulae with clinical relevance. RJPBCS. 2014 5(6):741-47.

[25] Sharma R, Sharma R, Singla RK, Kullar JS, Sharma T. Suprascapular notch: A morphometric and morphologic study in north Indian population. Int J Anat Res. 2015;3(3):1306-11.

[26] Tubbs RS, Smyth MD, Salter G, Oakes WJ. Anomalous traversement of the suprascapular artery through the suprascapular notch: a possible mechanism for undiagnosed shoulder pain? Med Sci Monit. 2000;9:116-19.

[27] Sangam MR, Sarda Devi SS, Krupadanam K, Anasuya K. A Study on the morphology of the suprascapular notch and its distance from the glenoid cavity. J Clin Diagn Res. 2013;7:189-92.
[28] Mistry P, Chauhan K., Mehta C, Patil D, Bansal M, Suthar K. A study of incidence of ossification of superior transverse scapular ligament of scapula and its clinical implications. Int J Basic \& Applied Med Sci. 2013;3:41-45.

[29] Kannan U, Kannan NS, Anbalagan J, Rao S. Study of suprascapular notch in indian dry scapulae with specific reference to the incidence of completely ossified superior transverse scapular ligament. J Clin Diagn Res. 2014;8:7-10.

[30] Vyas KK, Rajput HB, Zanzrukiya KM, Suttarwala I, Sarvaiya BJ, Shroff BD. An osseous study of suprascapular notch and various dimentions of safe zone to prevent suprascapular nerve injury. Ind J Applied Basic Med Sci. 2013;15(20):27.

[31] Thounaojam K, Karam R, Singh NS. Ossification of transverse scapular ligament. JEMDS. 2013;2(12):1790-91.

[32] Jadhav SD, Patil RJ, Roy PP, Ambali MP, Doshi MA. Suprascapular foramen in Indian dry scapulae. NJCA. 2012;1(3):133-35.

\section{AUTHOR(S):}
1. Dr. Apurba Patra
2. Dr. Manjeet Singh
3. Dr. Harsimarjit Kaur

\section{PARTICULARS OF CONTRIBUTORS:}

1. Senior Resident, Department of Anatomy, Government Medical College Patiala, India.

2. Professor and HOD, Department of Orthopaedics, MMIMSR, Mullana, India.

3. Associate Professor, Department of Anatomy, Government Medical College Patiala, India.
NAME, ADDRESS, E-MAIL ID OF THE CORRESPONDING AUTHOR:

Dr. Apurba Patra,

House no:15 E, Rajindra Medical Complex

New Lalbagh Colony Patiala, India.

E-mail: Apurba.cnmc03@gmail.com

FINANCIAL OR OTHER COMPETING INTERESTS: None. 